\title{
Diverse IgG serum response to novel glycopeptide epitopes detected within immunodominant stretches of Epstein-Barr virus glycoprotein 350/220: diagnostic potential of O-glycopeptide microarrays
}

\author{
Isotta D'Arrigo • Emiliano Cló • Tomas Bergström • \\ Sigvard Olofsson • Ola Blixt
}

Received: 12 October 2012 /Revised: 6 December 2012 / Accepted: 9 December 2012 /Published online: 8 January 2013

(C) Springer Science+Business Media New York 2013

\begin{abstract}
The Epstein-Barr virus (EBV) envelope glycoprotein 350/220 (gp350/220) is the most abundant molecule on the viral surface and it is responsible for the initial viral attachment to cell surface of the host. As many other viral envelope proteins, it is highly glycosylated, not least with Olinked glycans, most of which essential for EBV life cycle. EBV gp350/220 is also a primary target for neutralizing antibodies in the human hosts and a promising candidate for an EBV vaccine. Here we showed that recombinant GalNAc transferases can glycosylate scan peptides of the EBV gp350/220 envelope protein immobilized on microarray glass slides. We also identified serum IgG antibodies to a selection of peptides and O-glycopeptides, whereas sera from EBV-IgG negative individuals remained negative. We here describe novel glycopeptide epitopes present within immunodominant stretches of EBV gp350/220 and demonstrate a remarkable variability between individual samples with respect to their reactivity patterns to peptides and glycopeptides. The study
\end{abstract}

Electronic supplementary material The online version of this article (doi:10.1007/s10719-012-9465-3) contains supplementary material, which is available to authorized users.

I. D’Arrigo $・$ E. Cló $\cdot$ O. Blixt $(\bowtie)$

Department of Cellular \& Molecular Medicine,

Copenhagen Center for Glycomics, University of Copenhagen,

Copenhagen, Denmark

e-mail: olablixt@sund.ku.dk

T. Bergström $\cdot$ S. Olofsson

Department of Infectious Diseases, Section for Clinical Virology, Institute of Biomedicine, University of Gothenburg, Gothenburg, Sweden

Present Address:

E. Cló

Novo Nordisk A/S, Novo Nordisk Park,

DK-2760 Maaloev, Denmark provides additional insights into the complex B-cell response towards the EBV gp350/220 envelope protein, which may have implications for diagnostic and vaccine developments.

Keywords Epstein-barr virus (EBV) · Microarray ·

Glycopeptide · Biomarker · Serology · Glycosyltransferase · GALNT · Post-translational modification (PTM)

\section{Introduction}

EBV is an ubiquitous virus with a seroprevalence of $>90 \%$ in adults throughout the world [1]. EBV infections in immunocompetent individuals are usually subclinical, but may in some cases result in mononucleosis, a systemic febrile illness. Primary infections are followed by life-long persistence, which in healthy subjects is unproblematic [2]. In immunocompromised patients one feared EBV complication is an abnormal state of lymphocyte proliferation, i.e. posttransplantation lymphoproliferative disorder (PTLD) [3]. Moreover, EBV infection is studied in association with various disorders such as Multiple Sclerosis (MS) [4] as well as cancer [5]. The EBV envelope glycoprotein 350/220 (gp350/ 220) has been identified as a major immunodominant protein and a target for EBV-neutralizing antibody response, which may be of relevance for vaccine development $[6,7]$.

Viral envelope proteins are often glycosylated, and glycosylation is carried out in the ER-Golgi secretory pathway by host cell encoded glycosyltransferases [8]. The engagement of the host cell glycosylation machinery in biosynthesis of viral glycoproteins results in glycan structures that are tolerated by the host immune system [9]. However, virus infection may alter the host cell glycosylation machinery by disruption of the ERGolgi organization and/or induction of changes in expression of 


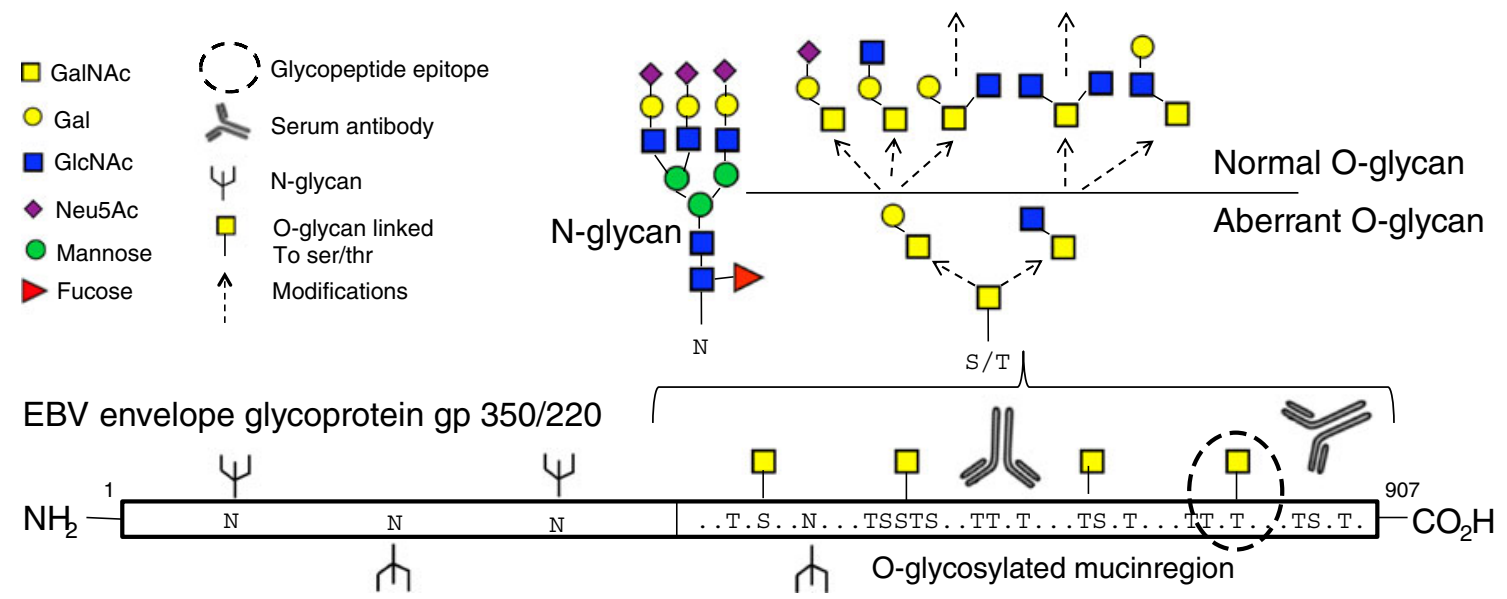

Fig. 1 Glycosylation of EBV glycoprotein gp350/220

required glycosyltransferase repertoire and thereby cause aberrant glycosylations (Fig. 1) [8]. We recently described that individuals infected with herpes simplex virus type 2 (HSV-2) raised an IgG response to a newly defined immunodominant and HSV-2 type specific O-glycopeptide epitope situated in the HSV-2 glycoprotein gG-2 [10]. There is evidence suggesting that this phenomenon represents the tip-of-the-iceberg of an undiscovered repertoire of epitopes primed by changes in the O-linked glycosylation of envelope proteins in the infected cell. Here, we have investigated in vitro O-glycosylation of scan peptides covering the entire EBVgp350/220 using recombinant GalNAc transferases (GTs) and compared the IgG immune response from EBV-seropositive subjects with seronegative individuals. We showed that peptides representing EBV gp350/220 could be O-glycosylated and identified a spectrum of EBV-specific IgG reactivities to both naked and Oglycosylated peptides.

\section{Materials and methods}

Synthetic peptide and glycopeptide microarrays Peptides and glycopeptides using glycosylated amino acid precursors (Fmoc-GalNAc $\alpha$ )-Ser/Thr (Sussex Research, OT, Canada) were prepared by a modified automated Fmoc-SPPS (SolidPhase Peptide Synthesis) methodology on a Syro II peptide synthesizer (MultiSynTech, Witten, Germany) as described previously [11]. Products were selectively enriched by immobilization onto amine reactive $N$-hydroxy succinimide (NHS) -activated hydrogel coated MPX16 glass slides (Schott Nexterion, SlideH) with a BioRobotics MicroGrid II spotter (Genomics Solution) using Stealth 3B Micro Spotting Pins (ArrayIt). Approximately $6 \mathrm{~nL}$ of glycopeptide/protein in print buffer $(150 \mathrm{mM}$ phosphate, $0.005 \%$ CHAPS, $0.03 \% \mathrm{NaN}_{3} \mathrm{pH} 8.5$ ) were deposited at 16 identical subarrays, $22 \times 22$ subgrid at $0.21 \mathrm{~mm}$ pitch between spots per slide format. After printing the slides were incubated at $70 \%$ humidity for $30 \mathrm{~min}$ and kept in freezer at $-25^{\circ} \mathrm{C}$ until used.

On-slide enzymatic O-glycosylation NHS-groups were deactivated in blocking buffer $(50 \mathrm{mM}$ ethanolamine in $50 \mathrm{mM}$ sodium borate, $\mathrm{pH} 8.5$ ) for $30 \mathrm{~min}$ then rinsed in Millipore water and spinned dry (VWR, Galaxy MiniArray). Blocked slides were fitted with adhesive superstructures (Schott Nexterion) to generate separated slide subarrays. Each subarray was filled with $50 \mu \mathrm{L}$ of O-glycosylation mixture: $500 \mathrm{ng}$ each of GT2 and GT3, $3.6 \mu \mathrm{L}$ of $100 \mathrm{mM}$ UDP-GalNAc (Sigma-Aldrich), $10.7 \mu \mathrm{L}$ of MilliQWater and $35.7 \mu \mathrm{L}$ of $5 \times$ Caco buffer (125 mM Cacodylate, $50 \mathrm{mM} \mathrm{MnCl}_{2}, 1.25 \%$ Triton-X-100, pH 7.4). Slides were covered with an adhesive slip and incubated for $2 \mathrm{~h}$ at $37^{\circ} \mathrm{C}$. Slides were then washed with PBS-Tween-20 (0.5\%) (5 min), rinse $3 \times$ in PBS, washed with MilliQWater (5 $\mathrm{min}$ ) and submerged in sodium citrate buffer (100 mM, pH 2.5) for 15 min while rocking. Slides were again washed with PBS-Tween and PBS, rinsed thoroughly with water and dried by centrifugation and immediately used in the binding assay below.

Binding assay and scanning Sera were collected and used to probe microarray slides displaying the EBV gp350/220 (glyco)peptides. Serum samples from EBV positive $(n=20)$ and EBV negative individuals $(n=20)$ were diluted $(1: 10)$ into incubation buffer PLI-P $(0.5 \mathrm{M} \mathrm{NaCl}, 3 \mathrm{mM} \mathrm{KCl}, 1.5 \mathrm{mM}$ $\mathrm{KH}_{2} \mathrm{PO}_{4}, 6.5 \mathrm{mM} \mathrm{Na} \mathrm{HPO}_{4}, \mathrm{pH}=7.4,3 \%$ BSA). Samples were directly added onto slide subarrays, $50 \mu \mathrm{L} /$ subarray. For primary and secondary staining, $50 \mathrm{uL}$ of VVA biotinylated lectins ( $2 \mathrm{mg} / \mathrm{mL}$, Vector Labs), goat anti-human IgG-Cy3 (Fc specific, $10 \mu \mathrm{g} / \mathrm{mL}$, Sigma-Aldrich) and Streptavidin-Cy3 ( $2 \mathrm{mg} / \mathrm{mL}$, Invitrogen) were diluted by volume in PLI-P, 1:1000, 1:500, 1:1000 respectively. All incubation steps were separated by one wash steps in PBS with $0.05 \%$ Tween-20 (PBS-Tween) and one in PBS. After the final wash, slides were spinned dry and scanned followed by image analysis and 
Fig. 2 On-slide enzymatic Oglycosylation of EBV gp350/ 220 scan peptides (20mer with 10 mer overlap) with recombinant GalNAcT2 and GalNAcT3. Red colored underlined amino acids sites on peptide sequences are predicted $\mathrm{O}$ glycosylation sites by NetOglyc algorithm. Bar graphs representing relative fluorescence values after VVA lectin staining
Seq. EBV gp350 scan peptide,

No 20aa10-mer overlap

ppGalNAc-transferase 2 ppGalNAc-transferase 3

\begin{tabular}{l|l}
\hline 1 & MEAALLVCQYTIQSLIHLTG
\end{tabular}

11 TIQSLIHLTGEDPGFFNVEI

21 EDPGFFNVEIPEFPFYPTCN

31 PEFPFYPTCNVCTADVNVTI

41 VCTADVNVTINFDVGGKK $\overline{\mathrm{H}} \mathrm{Q}$

51 NOAGŪ

1 NTDGGKKQLDLDFQLTP

1 LDLDFGQLTPHTKAVYQPRG

71 HTKAVYQPRGAFGGSENATN

1 AFGGSENATNLFLLELLGAG

LFLLELLGAGELALTMRSKK

ELALTMRSKKLPINVTTGEE

1 LPINVTTGEEQQVSLESVDV

1 OQVSLESVDVYFODVFGTMW

YFODVFTHW

C

YLIPETVPI I

YLIPETVPYIKWDNCNSTNI

KWDNCNSTNITAVVRAQGLD

TAVVRAQGLDVTLPLSLPTS

VTLPLSLPTSAQDSNFSVKT

AQDSNFSVKTEMLGNEIDIE

EMLGNEIDIECIMEDGEISQ

CIMEDGEI SOVLPGDNKFNI

VLPGDNKFNITCSGYESHVP

TCSGYESHVPSGGILTSTSP

SGGILTSTSPVATPI $\bar{P} G \bar{T} G Y$

VATPIPGTGYAYSLRLTPRP

AYSLRLTPRPVSRFLGNNNSI

VSRFLGNNNS I LYVFYSGNGP

LYVFYSGNGPKASGGDYCIO

KASGCDYCIOSNIVESDEIP

KASCGDYCIQSUIVESDEIP

SNIVESDEIPASQDMPINTT

ASQDMPTNTTDITYVGDNAT

DITYVGDNATYSVPMVTSED

YSVPMVTSEDANSPNVTVTA

ANSPNVTVTAFWAWPNNTET

FWAWPNNTETDFKCKWTLTS

DFKCKWTLTSGTPSGCENIS

GTPSCCENTSGA FASNRTED

GAR

GAFASTRDITVSCLGTAP

ITVSGLGTAPKILIITRTAT

KTLIITRTATNATTTTHKVI

NATTTTHKVIFSKAPESTTT

FSKAPESTTTSPTLNTTGFA

SPTLNTTGFADPNTTTTGLPS

DPNTTTGLPSSTHVPTNLTA

STHVPTNLTAPĀSTG $\bar{P} T V \bar{S} T$

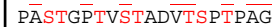

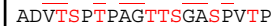

TTSGASPVTPSPSPWDNGTE

SPSPWDNGTESKAPDMTSST

SKAPDMTSSTSPVTTPTPNA

SPVTTPTPNATSPTPAVTTP

TSPTPAVTTTPTPNĀTSPTPA

TPNĀTSPTPAVTTTPTPNÄTS

VTTPTPNATSPTLGKTSPTS

PTLGKTSPTSAVTTPTPNAT

PTLGKTSPTSAVTTPTPNAT
AVTTPTPNATSPTLGKTSPT

AVTTPTPNATSPTLGKTSPT
SPTLGKTSPTSAVTTPTPNA

SPTLGKTSPTSAVTTPTPNA
SAVTTPTPNATSPTLGKTSP

TSPTLGKTSPTSAVTTTPTPN

TSAVTTPTPNATGPTVGETS

ATGPTVGETSPQANĀTNHTL

PQ̄ANĀTNHTLGGTSPT̄PVVTT

GGTSPTPVVTSOPKNĀTSAV

SQPKNATSAVTTGQHNITSS

TTGQHNITSSSTSSMSLRPS

STSSMSLRPSSNEETLSPST

SN̄PETLSPSTS̄DNST'SHMP

SDNSTSHMPLLTSAHPTGGE

LTSAHPTGGENITOVTPASI

NITTOVT $\bar{D} A S T S T \bar{H} H \overline{S T T S P}$

STHU STS

TPP

APRPG TISQA.SGPGSSTST

SGPGNSSTSTKPGEVNVTKG

KPGEVNVTKGTPPQNATSPQ

TPPQNATSPQAAPSGQKTAVP

APSGQKTAVPTVTSTGGKAN

TVTSTGGKANSTTTGEKHTTG

STTGGKHTTGHGARTSTEPT

HGARTSTEPTTDYGGDSTTP

HGAR -

TDYGGDSTI RPRYNATTYL

RPRYNATTYLPPSTSSKLRP

PPSTSSKLRPRWTFTSPPVT

RWTFTSPPVTTAQATVPVP $\bar{P}$

TAQATVPVP $\overline{T T S Q P R F S N L S}$

TSQPRFSNLSMLVLQWASLA

MLVLOWASLAVITLLLILVM

VL

VLTLLLLLVMADCAFRRNLS

ADCAFRRNLSTSHTYTTPPY

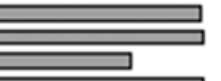

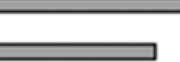

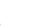

\section{.}
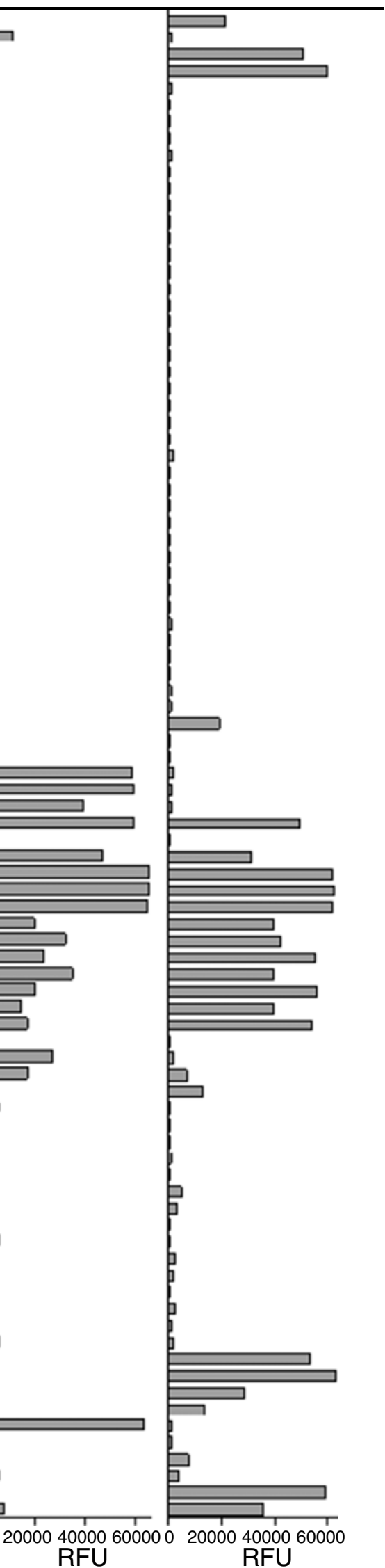

0 200004000000000 RFU
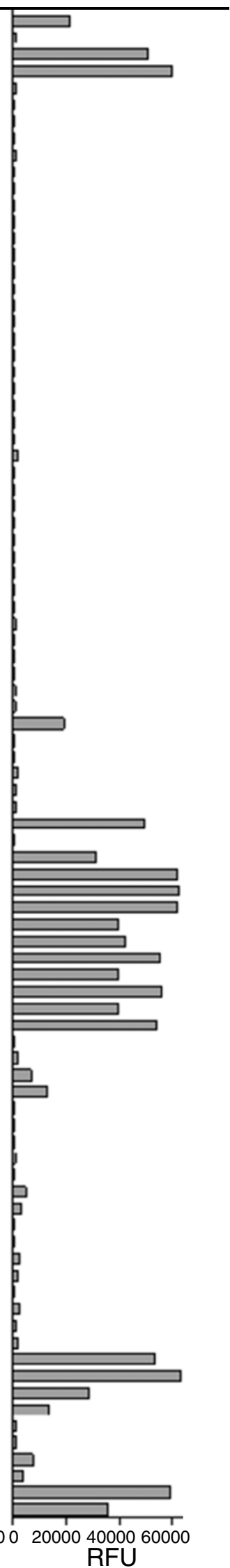

Springer 
quantification. The slides were scanned using a ProScanarray microarray scanner (Perkin Elmer) equipped with 3 lasers for excitation at $488 \mathrm{~nm}, 543 \mathrm{~nm}$ or $633 \mathrm{~nm}$, respectively, and images were analyzed with ScanArray Express software. For cyanine 3 fluorescence, $543 \mathrm{~nm}$ (excitation) and $570 \mathrm{~nm}$ (emission) were used. Spots were identified using automated spot finding with manual adjustments for occasional irregularities. The final data output is gained from the mean spot Relative Fluorescence Units (RFU) from 3 replicate spots and spot intensities were determined by subtracting the median pixel intensity of the local background from the average pixel intensity within the spot. The quality control covered intraand inter-chip quality analysis of replicates and CV (coefficient of the variation) was generally $<10 \%$ of targets. For peptides selected, patients with relative fluorescent value higher than two standard deviations over the mean of the control group were designated as positive.

Inhibition assay Three inhibition solutions were prepared in serial dilutions 1:4 by volume in $50 \mu \mathrm{L}$ PLI-P (starting concentration $12.5 \mu \mathrm{g}$ of inhibitor) and mixed with EBV + ve sera (no. \#16) diluted 1:20 in PLI-P. Incubation time of $1 \mathrm{~h}$ followed by one wash step in PBS-Tween and one in PBS. Bound IgG was detected with Anti-Human-IgG-Cy3 diluted 1:500 in PLI$\mathrm{P}(50 \mu \mathrm{L} /$ subarray $)$ for $1 \mathrm{~h}$. Final wash step in PBS-Tween-20 and a brief rinse with de-ionized water and slides were spun dry.

\section{Results and discussion}

Previous screening of human sera against recombinant fusion protein fragments of gp350/220 revealed presence of commonly recognized B-cell epitopes localized to the carboxy-terminal third of the protein [12] but failure to detect peptide antibodies using ELISA suggest either conformational or glycosylation dependent recognition [13]. We recently established efficient synthetic protocols for covalent site-directed display of peptides onto hydrophilic and biocompatible microarray surfaces $[11,14]$. Our concept also allows direct on-slide enrichment from cleaved and crude Solid-Phase Peptide Synthesis mixtures, offering a procedure to rapidly study complete sets of sequences from target proteins without tedious purification protocols. The array surface enrichment also allows for correct glycopeptide structures to be immobilized successfully even during less successful reaction conditions (lower yields). Following

Fig. 3 EBV serum IgG reactivity against overlapping peptides covering sequence 731-790. EBV-IgG + ve sera, $n=20$ (grey columns); EBV-IgG - ve sera, $n=20$ (white columns). Each bar graph represent the average of three replicate spots on slide for each serum with error bars as standard deviation
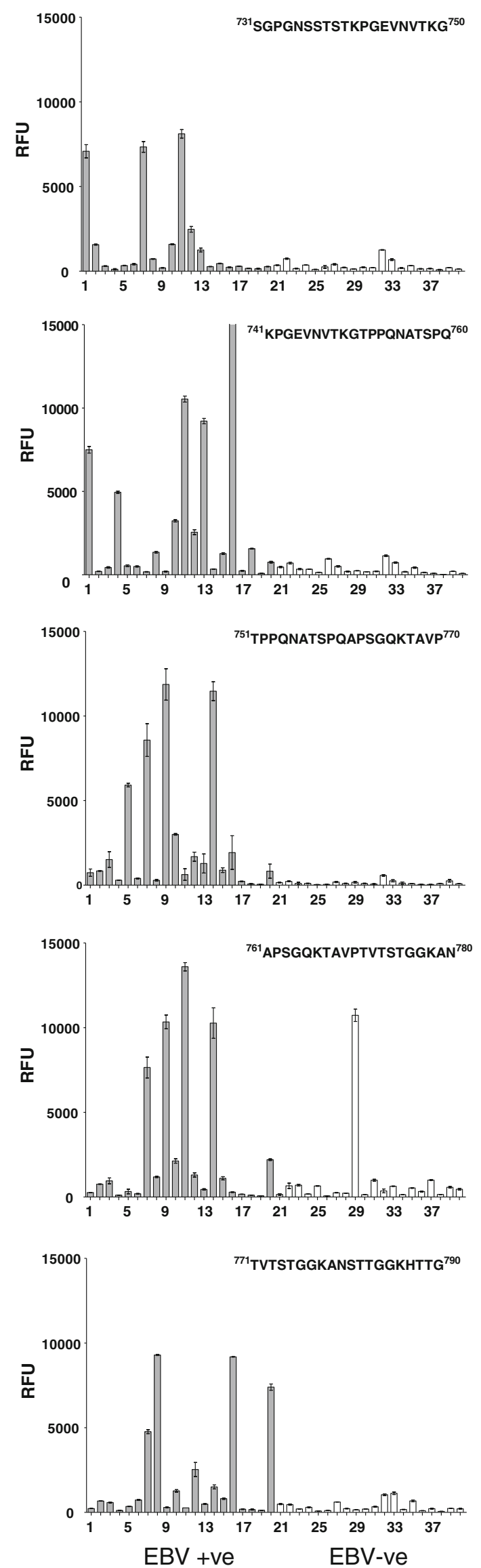
this strategy, we synthesized 20mer with 10 mer overlapping scan peptides (Fig. 2), representing the entire gp350/220 envelope protein and covalently displayed them via NHSactivated hydrogel coated glass slides in a 16-well patterned layout (see "Materials and Methods"). The identity of the unglycosylated peptides was confirmed with MALDI-TOF on randomly selected crude peptides (Data not shown).

An efficient approach to obtain O-glycosylated peptides for biological studies is provided by enzymatic O-glycosylation of peptides using recombinant GTs [15]. The initiating enzymes, from the GalNAc-tranferase (GalNAcT) family have also been shown to work well on solid-phase substrates such as beads [16] and glass surfaces with retained substrate specificities [11, 17]. In our previous study involving the HSV-2 glycoprotein G (gG-2) the enzymatic on-chip Tnglycosylation with GT2 correlated well with the mucin related peptides [10]. Here, we utilized two GalNAcTs, GT2 and GT3 [15] to glycosylate gp350/220 sequences displayed on the glass chip. Both enzymes are documented to have broad acceptor specificities to mucin type peptides frequently containing S,T,P,V and A amino acids [18, 19]. Thus, the on-chip experiments, using the lectin VVA isolectin B4, showed an extensive $\mathrm{O}$-glycosylation in sequence areas delimited by 451 to 601 , containing frequent appearance of S,T,P,V and A amino acids (Fig. 2). This observation was in line with the prediction by, the NetOglyc prediction algorithm (v3.0) [20], suggesting this region to be extensively glycosylated. The subsequent region 621-780, also predicted to be glycosylated but with less frequency due to the presence of other nonmucin related amino acids, also showed much lower glycosylation rate using GT2 and GT3. Additional enzyme isotypes might be necessary to extend glycosylation on these peptides. Although the two enzymes in our study had many overlapping specificities (peptides from 481 to 601 ) there were also unique O-glycosylation patterns; peptides from 1 to 31 , from 801 to 831 and from 881 to end of protein are GT3 substrates, whereas peptide from 451 to 471 and peptide 841 are glycosylated by GT2 only. A few selected peptides $(521,661,841)$ with positive and negative enzyme reactivity were also glycosylated in solution to confirm on-chip reactivity. MALDI-TOF spectra showed the introduction of GalNAc sugar on peptide 521 (4 sites) and 841 (1 sites) and no Tn-glycosylation of 661 was found (data not shown) which were confirmed by the VVA staining on chip (Fig. 2).

To first address presence of serum anti-gp350/220 IgG antibody response to displayed peptides, we analyzed EBV-

Fig. 4 Serum $\mathrm{IgG}$ reactivity on chemical site-specific glycopeptides of sequence 841. O-glycosylation sites of GalNAc are indicated with a yellow box. EBV-IgG + ve sera, $n=20$ (grey columns); EBV -ve sera, $n=20$ (white columns). Each bar graph represent the average of three replicate spots on slide for each serum with error bars as standard deviation
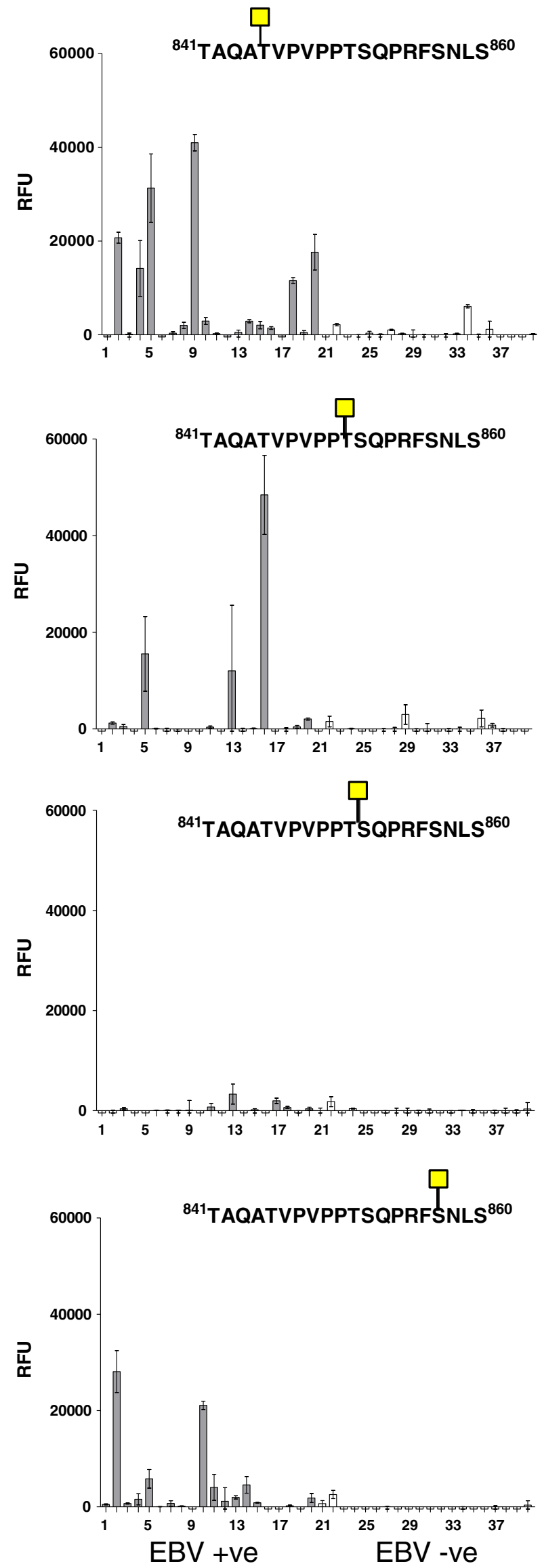
Fig. 5 Serum $\operatorname{IgG}$ Inhibition assay with peptide 841 and glycopeptides. Staining was performed with patient serum $\# 16$ at 1:20 dilution and inhibitors were added from $0.0 \mu \mathrm{g}$ to $0.781 \mu \mathrm{g}$ in 4-fold increments. Bold underlined letters point out O-glycosylation site on peptides

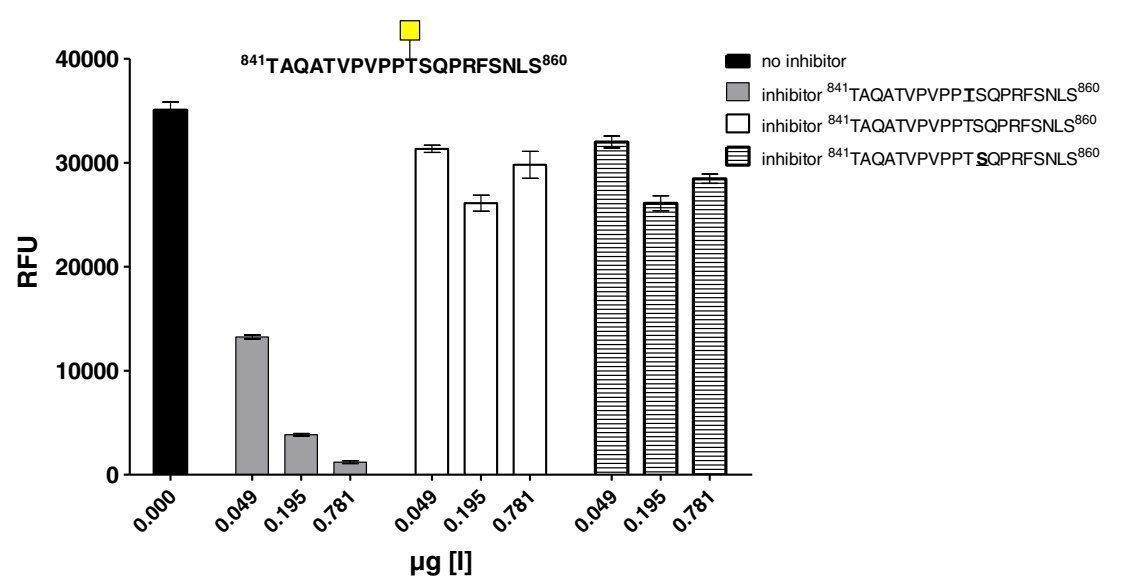

$\operatorname{IgG}+\mathrm{ve}(n=20)$ and EBV-IgG $-\mathrm{ve}(n=20)$ serum samples, confirmed by indirect immunofluorescence [21], on the nonglycosylated chip. By evaluating all sera against each peptide in two independent experiments, we identified increased IgG reactivities in EBV + ve sera localized within the 731-790 sequence, which re-confirmed the position of an immune dominant sequence at $C$-terminal region of gp350/220 protein, previously identified by Zhang and coworkers [22]. In Fig. 3 we showed that EBV-IgG + ve sera had high IgG reactivites to 10 mer overlapping sequences of the 731-791 region compared with the essentially nonreactive EBV-IgG -ve sera. We found a remarkable interindividual reactivity to different peptides. For example, peptide 731 was reactive for three EBV-positive sera (\#1, $\# 7, \# 11$ ), whereas the 20 -mer peptide 741 reacted with five EBV-positive sera (\#1, \#4, \#11, \#13, \#16). Interestingly, peptide 751 bound to a different set of sera (\#5, \#7, \#9, $\# 14$ ) and peptide 761 reacted with sera \#7, \#9, \#11 and \#14. The last sequence of this region, covered by peptide 771 , showed additional reactivity to sera (\#7, \#8, \#16, \#20). All together, we demonstrated a pattern of individual reactivites to a restricted peptide stretch not glycosylated by GT2/T3 or predicted by the NetOglyc algorithm. Peptide reactivities to other parts of the protein were seen for both EBV-IgG + ve and EBV-IgG -ve sera, suggesting non-EBV related cross- reactivities by other serum antibodies (Supplementary S1).

Next, the same serum set was evaluated after enzymatic on-chip Tn-glycosylation of scan peptides and increased reactivities were found for peptide sequences 821-841. Evaluation of individual sera showed that four EBVpositive sera produced a distinct reactivity to the peptide glycosylated by the GT2/T3 reaction (sera \#1, \#3, \#7, \#20) but not to the naked peptide (Supplementary S2). Addition of GalNAc residues to peptide 841 was ascertained by (i) VVA B4 isolectin binding and (ii) by reproduction of GT2/ T3 enzymatic O-glycosylation (1 sites) in solution as monitored by MALDI-TOF (data not shown). To further characterize the epitope properties of peptide 841 , we chemically synthesized four Tn-glycosylated glycopeptide variants of the 841 sequence with site-specific Tnglycosylation at position $\mathrm{T}^{845}, \mathrm{~T}^{851}, \mathrm{~S}^{852}$ and $\mathrm{S}^{857}$, respectively, and evaluated the contribution of glycosylation at each site with respect to the reactivity with EBV-positive sera. As shown in Fig. 4, the site of Tn-glycosylation affected reactivity with EBV-positive sera. Glycosylation at $\mathrm{T}^{845}$ showed reactivities for serum $\# 2, \# 4, \# 5$, \#9 and $\# 20$, whereas glycosylation at $\mathrm{T}^{851}$ only reacted with serum from three individuals (\#5, \#13 and \#16). The third Tn-glycopeptide $\left(\mathrm{S}^{852}\right)$, did not react with any sera whereas the Tn-glycosylation at $\mathrm{S}^{857}$ were positive for two sera (\#2 and \#10).
Fig. 6 Dot-plot of cumulative intensities of selected peptides and glycopeptides comparing EBV-IgG + ve and EBV-IgG ve serum. Bold and underlined letters on peptide sequences point out O-glycosylation sites on chemical glycopeptides. Line on $\log =1024$ is average background signal and line on $\log =4096$ is the diagnostic cut-off

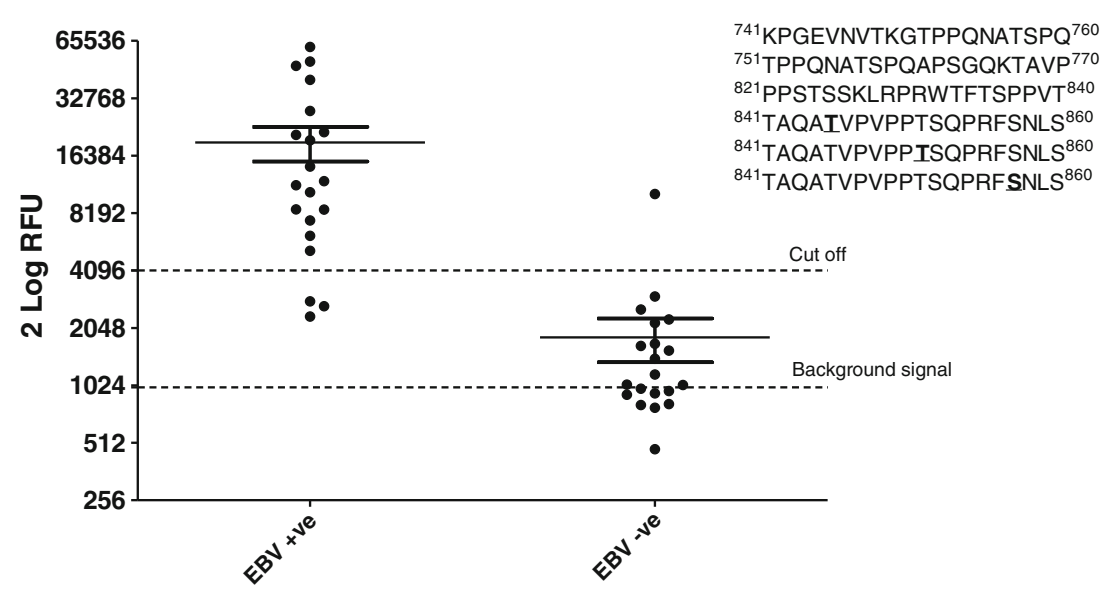


To further establish that the monosaccharide is part of the recognition epitope we performed a series of competitive inhibition experiments with selected chemically synthesized glycopeptides $\left(\mathrm{T}^{851}, \mathrm{~S}^{852}\right)$ of 841 and the naked sequence (Fig. 5). We found that serum reactivity to glycopeptide $\mathrm{T}^{851}$ was inhibited by the identical glycopeptide but not by the naked peptide or if glycan site was altered (glycopeptide $\mathrm{S}^{852}$ ) indicating that Tn-glycosylation at $\mathrm{T}^{851}$ was required for this serum sample to react with peptide 841 . These data suggest that differences in Tn-glycosylation of EBV gp350/ 220 , possibly reflecting different idiotypic expression patterns of GalNAc transferases in the EBV target cells in EBVinfected individuals, and contribute to the heterogenous serum reactivity described above. In parallel, individual variations in the activities of peptide processing proteins such as proteasomes, peptide transporters to ER-Golgi and antigen presenting MHC class I/II molecules can be also responsible for the heterogeneity in immune response to EBV infection reported here and certainly produce distinct sets of antigenic peptides with and without O-glycosylation [23, 24].

Current methods for serological diagnosis are based either on detection of antibodies that are specific for EBV proteins and glycoproteins of detection of heterophile antibodies, non-related to EBV antigens, but induced as a consequence of unspecific expansion of EBV-transformed B cells in the infected individual [25]. Assays based on recombinant (glyco)protein or synthetic (glyco)peptide antigens tend to be more specific than those using whole or disrupted virus particles [26]. In this work we showed that assaying serum reactivity to EBV gp350/220 scan peptides and glycopeptides displayed on microarrays could be a valid strategy for development of improved EBV serology. Although the present study did not include any recombinant or isolated gp350/220 protein for comparison we made a cumulative combination of the most reactive sequences (Fig. 6) and compared EBV + ve and -ve sera. We selected peptides with differential reactivity in the identified naked immunodominant region (741-771 and 821) and glycopepides of sequences 841 . In combination and at a cut-off value of $4000 \mathrm{RFU}$, these sequences showed high reactivity in EBV + ve sera, 17 out of $20,(85 \%)$ and 1 out of $20(5 \%)$ false positive. Thus, the individual antigenic peptides and glycopeptides analysed here could not be used as serological test, due to their scattered reactivity with individual sera, but the combination of them generated a unique fingerprint to detect a majority of EBV + ve sera and is comparable to available commercial systems used for EBV sero-diagnosis [27]. Also, the individual immune responses towards glycopeptide epitopes may further increase understanding of immune reactivity potentially important towards generation of EBV vaccines [28, 29].

In summary, our study reveals a diverse individual B-cell antibody reactivity to EBV gp350/220 peptides and glycopeptides and in combination, they could differentiate EBV infected from non-EBV infected individuals. One protein may not detect all the antibodies elicited in humans to a particular infection because variation in titer and timing of antibody responses and studies to other envelope proteins on the same virus should be performed to improve monitoring the disease [30].

Acknowledgments This work was supported by, The Benzon Foundation, The Danish Agency for Science, Technology and Innovation (FTP), EU FP7/2007-2013-EuroGlycoArrays 215536, EU FP7GlycoBioM and University of Copenhagen Programme of Excellence.

\section{References}

1. Gandhi, M.K.: Epstein-Barr virus-associated lymphomas. Expert Rev. Anti-Infect. Ther. 4(1), 77-89 (2006)

2. Kieff, E.B., Rickinson, A.B.: Epstein-Barr virus and its replication. In: Knipe, D.M., Howley, P.M. (eds.) Fields Virology, 5th edn, pp. 2603-2654. Lippincott-Raven, Philadelphia (2007)

3. Smets, F., Sokal, E.M.: Epstein-Barr virus-related lymphoproliferation in children after liver transplant: role of immunity, diagnosis, and management. Pediatr. Transplant. 6(4), 280-287 (2002)

4. Disanto, G., et al.: Epstein-Barr virus, latitude and multiple sclerosis. Mult. Scler. (2012)

5. Young, L.S., Rickinson, A.B.: Epstein-Barr virus: 40 years on. Nat. Rev. Cancer 4(10), 757-768 (2004)

6. Sokal, E.M., et al.: Recombinant gp350 vaccine for infectious mononucleosis: a phase 2, randomized, double-blind, placebocontrolled trial to evaluate the safety, immunogenicity, and efficacy of an Epstein-Barr virus vaccine in healthy young adults. J. Infect. Dis. 196(12), 1749-1753 (2007)

7. Jackman, W.T., Mann, K.A., Hoffmann, H.J., Spaete, R.R.: Expression of Epstein-Barr virus gp350 as a single chain glycoprotein for an EBV subunit vaccine. Vaccine 17(7-8), 660-668 (1999)

8. Olofsson, S., Hansen, J.E.: Host cell glycosylation of viral glycoproteins - a battlefield for host defence and viral resistance. Scand. J. Infect. Dis. 30(5), 435-440 (1998)

9. Merry, T., Astrautsova, S.: Alternative approaches to antiviral treatments: focusing on glycosylation as a target for antiviral therapy. Biotechnol. Appl. Biochem. 56(3), 103-109 (2010)

10. Clo, E., et al:: Characterization of the viral O-glycopeptidome: a novel tool of relevance for vaccine design and serodiagnosis. J. Virol. 86(11), 6268-6278 (2012)

11. Blixt, O., et al.: A high-throughput O-glycopeptide discovery platform for seromic profiling. J. Proteome Res. 9(10), 5250$5261(2010)$

12. Pither, R.J., et al:: Mapping of B-cell epitopes on the polypeptide chain of the Epstein-Barr virus major envelope glycoprotein and candidate vaccine molecule gp340. J. Virol. 66(2), 1246-1251 (1992)

13. Zhang, P.F., Marcus-Sekura, C.J.: Conformation-dependent recognition of baculovirus-expressed Epstein-Barr virus gp350 by a panel of monoclonal antibodies. J. Gen. Virol. 74(Pt 10), 2171-2179 (1993)

14. Blixt, O., et al.: Printed covalent glycan array for ligand profiling of diverse glycan binding proteins. Proc. Natl. Acad. Sci. U. S. A. 101(49), 17033-17038 (2004)

15. Bennett, E.P., et al:: Control of mucin-type O-glycosylation: a classification of the polypeptide GalNAc-transferase gene family. Glycobiology 22(6), 736-756 (2012)

16. Gerken, T.A., Raman, J., Fritz, T.A., Jamison, O.: Identification of common and unique peptide substrate preferences for the UDP- 
GalNAc:polypeptide alpha-N-acetylgalactosaminyltransferases T1 and T2 derived from oriented random peptide substrates. J. Biol. Chem. 281(43), 32403-32416 (2006)

17. Laurent, N., et al.: Enzymatic glycosylation of peptide arrays on gold surfaces. ChemBioChem 9(6), 883-887 (2008)

18. Gerken, T.A., Tep, C., Rarick, J.: Role of peptide sequence and neighboring residue glycosylation on the substrate specificity of the uridine 5 '-diphosphate-alpha- $\mathrm{N}$-acetylgalactosamine:polypeptide $\mathrm{N}$-acetylgalactosaminyl transferases $\mathrm{T} 1$ and $\mathrm{T} 2$ : kinetic modeling of the porcine and canine submaxillary gland mucin tandem repeats. Biochemistry 43(30), 9888-9900 (2004)

19. Gerken, T.A., Gilmore, M., Zhang, J.: Determination of the sitespecific oligosaccharide distribution of the O-glycans attached to the porcine submaxillary mucin tandem repeat. Further evidence for the modulation of O-glycans side chain structures by peptide sequence. J. Biol. Chem. 277(10), 7736-7751 (2002)

20. Julenius, K., Molgaard, A., Gupta, R., Brunak, S.: Prediction, conservation analysis, and structural characterization of mammalian mucin-type O-glycosylation sites. Glycobiology 15(2), 153164 (2005)

21. Wyatt, D.E., Brooker, D.S., Connolly, J.H., Coyle, P.V.: Prognostic value of Epstein-Barr virus serology in patients with nasopharyngeal carcinoma. J. Infect. 26(2), 171-175 (1993)

22. Zhang, P.F., et al.: Mapping of the epitopes of Epstein-Barr virus gp350 using monoclonal antibodies and recombinant proteins expressed in Escherichia coli defines three antigenic determinants. J. Gen. Virol. 72(Pt 11), 2747-2755 (1991)
23. York, I.A., Rock, K.L.: Antigen processing and presentation by the class I major histocompatibility complex. Annu. Rev. Immunol. 14, 369-396 (1996)

24. Del-Val, M., Lopez, D.: Multiple proteases process viral antigens for presentation by MHC class I molecules to CD8(+) T lymphocytes. Mol. Immunol. 39(3-4), 235-247 (2002)

25. De Paschale, M., Clerici, P.: Serological diagnosis of Epstein-Barr virus infection: Problems and solutions. World J. Virol 1(1), 31-43 (2012)

26. Hess, R.D.: Routine Epstein-Barr virus diagnostics from the laboratory perspective: still challenging after 35 years. J. Clin. Microbiol. 42(8), 3381-3387 (2004)

27. de Ory, F., Guisasola, M.E., Sanz, J.C., Garcia-Bermejo, I.: Evaluation of four commercial systems for the diagnosis of Epstein-Barr virus primary infections. Clin. Vaccine Immunol. 18 (3), 444-448 (2011)

28. Freeman, M.L., et al.: Importance of antibody in virus infection and vaccine-mediated protection by a latency-deficient recombinant murine gamma-herpesvirus-68. J. Immunol. 188(3), 10491056 (2012)

29. Cohen, J.I., Fauci, A.S., Varmus, H., Nabel, G.J.: Epstein-Barr virus: an important vaccine target for cancer prevention. Sci. Transl. Med. 3(107), 107fs107 (2011)

30. Sitompul, L.S., Widodo, N., Djati, M.S., Utomo, D.H.: Epitope mapping of gp350/220 conserved domain of epstein barr virus to develop nasopharyngeal carcinoma (npc) vaccine. Bioinformation 8(10), 479-482 (2012) 